Brit. J. prev. soc. Med. (1974), 28, 180-186

\title{
The new chronic psychiatric population
}

\author{
ANTHEA M. HAILEY \\ MRC Social Psychiatry Unit, Institute of Psychiatry, De Crespigny Park, London SE5
}

\section{SUMMARY}

Data from the Camberwell Register are used to examine the accumulation of a new chronic population in three forms of psychiatric careinpatient, day patient, and hostel care. For the period 1964-72, against the background of expanding psychiatric services, the number and characteristics of new long-stay patients in each form of care are analysed. The net accumulation of new long-stay inpatients stabilized after a few years; the population of long-stay day patients and residents in psychiatric hostels was still increasing. The epidemiological basis of the study allows the numbers to be expressed as rates per head of population.

\section{INTRODUCTION}

This paper forms the companion to an earlier study of the decrease of a long-stay mental hospital population from Camberwell (Hailey, 1973). The data are derived from the Camberwell Psychiatric Case Register, details of which have been published elsewhere (Wing, Bramley, Hailey, and Wing, 1968; Wing and Hailey, 1972).

In order to make decisions about the future provision of psychiatric beds, it is necessary to have data not only on the rate at which the 'old' long-stay population is declining, but also on the number of 'new' long-stay patients who are accumulating as replacement. A number of workers have reported data on new long-stay inpatients. Mezey and Evans (1968) studied admissions to Claybury mental hospital from an area of north London over two separate periods; the data were intended as a clarification of the changing role of the mental hospital. Cross and Yates (1961), in an early study in Birmingham, presented data from which they derived statistical projections of future bed requirements; later work reported by Cross, Hassall, and Spencer (1970) from Powick Hospital, Worcester developed the same themes. Magnus (1967) carried out a study of new chronic patients at Glenside Hospital, Bristol; his general findings were in line with those of other workers: elderly females and schizophrenic males formed the two largest groups in this new chronic population.

The purpose of this article is to present epidemiological data from the Camberwell area of London for the period 1964-72. From the register we have obtained figures not only on the accumulation of a new long-stay inpatient population but also of a similar group at psychiatric day hospitals and day centres and at hostels. A consideration of all this material together provides a more comprehensive view of the problem of the chronic patient than is obtained from an analysis of inpatient care only.

\section{Psychiatric Services in Camberwell}

The development of a district psychiatric service for Camberwell, based on the Bethlem-Maudsley and St. Francis' hospitals, has been documented in detail elsewhere (Hailey, Wing, and Wing, 1970; Wing and Hailey, 1972). It is only necessary here, therefore, to describe the principal changes that have taken place in order to give the context for the material. From 1964 to the middle of 1967 most inpatient admissions from Camberwell were to the catchment area mental hospital, Cane Hill. St. Francis' was an observation ward; a number of patients were admittted to Bethlem or Maudsley, and a very few to other London mental hospitals. From the end of 1967 onwards, the Bethlem-Maudsley and St. Francis' began to take catchment area responsibility for Camberwell: St. Francis' was to serve as a local medium- and longer-stay inpatient unit, and its observation function ceased. Admissions from Camberwell to Cane Hill were therefore reduced. From April 1970 full catchment area responsibility was assumed by the three hospitals, except for a small agreed number of admissions to Cane Hill each year, mainly for psychogeriatric or severe schizophrenic patients. The Camberwell Register has constituted a monitoring system for these changes. 
Over the same period there has been an expansion in local day services for psychiatric patients. A rehabilitation workshop was set up in 1967 alongside the existing Maudsley Day Hospital; the two local authority day centres have expanded, and these, too, are included in the Register system so that a comprehensive picture of all specialist services is maintained.

The number of hostel places for the mentally ill from Camberwell is very limited, and the local authority pays for residential care in hostels run by the Mental After-care Association or the Richmond Fellowship, for example. These hostels are scattered around south-east England. In 1971 a local housing association was set up in Camberwell to establish and maintain houses to accommodate people suffering from psychiatric illness. These are included as 'hostels' on the Register and will be shown in the data to be presented.

\section{Definitions}

As in the previous article, our definition of a 'long-stay' patient is one who had remained continuously in a particular form of psychiatric care for one year or more-as either an inpatient, or a day patient, or a hostel resident. The analysis does not include those with long 'episodes' during which they may have had a series of different types of care; this is quite a different question and requires a more complex form of analysis.

In measuring length of inpatient stay we ignore short periods of a few days on trial leave or weekend leave if the patient then returned to hospital. In addition, it is recognized that there are some patients who attend a rehabilitation centre or even go out to work during the day while technically they are still inpatients, and may statistically become long-stay inpatients.

For day care the time measured is the period for which the patient is 'on the books' and attending regularly, although not necessarily every day. Short periods of sick leave or a week off, for example at Christmas, are ignored. A person may attend a day centre at the same time as having occasional psychiatric outpatient contacts; the Register record enables us to measure a continuous period of day centre or day hospital attendance.

A person in a psychiatric hostel some way away from Camberwell, perhaps in Brighton, is unlikely to be also attending Camberwell psychiatric services; however, someone in the local Housing Association accommodation is almost certainly also attending psychiatric services. The data allow the measurement of length of stay at the hostel, or locally the length of tenure of the special accommodation.

The data concern the three groups of long-stay inpatients, long-stay day patients, and long-stay hostel residents on census days; these groups are, as it turns out, mutually exclusive on each census day, although theoretically it is possible for the Register to show a patient simultaneously as a long-stay day patient and hostel resident.

\section{INPATIENTS}

It is possible, from national statistics, to look at changes in the number of patients in mental hospitals who have a length of stay of between one and three years on a given day-one suitable definition for 'new chronic patients'. Table I gives figures for 31 December of specified years and shows numbers and rates. Camberwell data

TABLE I

INPATIENTS ON CENSUS DAYS, WITH A STAY OF ONE BUT IESS THAN THREE YEARS ON THAT DAY, CAMBERWELL, AND ENGLAND AND WALES

\begin{tabular}{|c|c|c|c|c|}
\hline & \multicolumn{2}{|c|}{ Camberwell } & \multicolumn{2}{|c|}{ England and Wales } \\
\hline & No. & Rate* & No. & Rate* \\
\hline 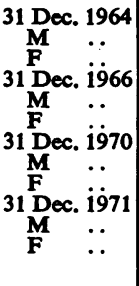 & $\begin{array}{r}13 \\
56 \\
12 \\
47 \\
11 \\
22 \\
6 \\
19\end{array}$ & $\begin{array}{r}15 \cdot 7 \\
61 \cdot 7 \\
14 \cdot 6 \\
52 \cdot 1 \\
13 \cdot 6 \\
24 \cdot 7 \\
7 \cdot 5 \\
21 \cdot 4\end{array}$ & $\begin{array}{l}6261 * * \\
9995 \\
5860 * * * \\
9561 \\
\\
5640^{* * * *} \\
9197\end{array}$ & $\begin{array}{l}26 \cdot 8 \\
40 \cdot 5 \\
24 \cdot 6 \\
38 \cdot 0 \\
23 \cdot 8 \\
36.6\end{array}$ \\
\hline
\end{tabular}

*Rates are given per 100,000 home population of that sex. Sources: DHSS, 1970

*** DHSS, 1972

**** DHSS, 1973

are shown for matching years, and for 1964 when the Register began. The national rate for females is higher than for males; for both sexes rates show a decrease over time. The same is true of Camberwell, although the excess of females is much more marked. However, the decrease in female rates for the area over time is very striking; we shall see that this is largely due to a decreasing number of elderly women who became long-stay.

By 1970-71 the Camberwell rates for both sexes are much lower than those for England and Wales. We should perhaps expect Camberwell to have relatively fewer 'new chronic' patients than the country as a whole, particularly with the 
development of local inpatient services; but it must also be pointed out that the actual numbers are very small and so the calculation of rates is perhaps rather unsatisfactory.

The age characteristics of the Camberwell and national groups for 1971, taking both sexes together, were very similar. Some $32 \%$ of Camberwell patients were aged under 55 years, $32 \%$ were between 55 and 74 years, and $36 \%$ were 75 years or older. The corresponding figures for England and Wales were $31 \%, 34 \%$, and $35 \%$. Clearly, some alternative to mental hospital care for the elderly would greatly reduce the numbers of new long-stay patients.

In Table II we show year by year data from Camberwell, divided according to three broad diagnostic groups. For 1965-71 admissions, that is, taking the data to the end of 1972 , percentage figures are also given in the table to show the proportion of all admissions within the diagnostic group which lasted a year or more. The only admissions from 1964 which appear on the Register are for those people who were in the original census of 31 December 1964; some of these remained into 1965 or longer to become new longstay patients, but of course no base data are available from which to derive proportions of all admissions that year.

For dementia both the numbers and percentages have been decreasing over time. Most of these patients were elderly females; this decrease corresponds to the decline in numbers of females in the year by year censuses in Table I. For diagnoses other than dementia, or schizophrenia, there is no clear trend over the years although a gradual increase has taken place since 1967.

The third group, schizophrenia, is remarkable in that an apparently declining trend was suddenly reversed in 1971 when $10 \%$ of all admissions for schizophrenia were for long-stay inpatient care. This phenomenon appears to be a direct result of the district services; most of the increase of 1971 over 1970 took place at St. Francis' Hospital. The majority of these were chronic schizophrenic patients who had a long history of psychiatric care; several were living at the hospital while attending the Maudsley Day Hospital (just up the road). The excess of 1971 over 1970 new long-stay admissions was almost entirely in the younger age groups-under 45 years.

The effect of the developing district service and the change in policy has been gradually to reduce the number of new long-stay admissions to Cane Hill, with Bethlem, Maudsley, and St. Francis' providing some long-term care for Camberwell patients. Thus nine of the 30 long-stay admissions in 1970 were to the district hospitals, and 15 of the 42 in 1971.

Contrary to some arguments, the provision of psychiatric beds locally (for example, at a district general hospital unit) does not necessarily reduce the length of inpatient care for all patients. There are some patients for whom the advantage of being in hospital locally is that other local services can contribute to their treatment, and that, if they stay in for a long period, they do not become cut off from local friends and family as they would do at a distant mental hospital. Clinicians in Camberwell felt that these people were probablyo receiving a better standard of care than previously. A long inpatient spell gave the patients more security and support than frequent short periods in hospital, the general pattern of care they had received in the past.

The concept of the 'accumulation' of new longstay patients is a useful one as it indicates the extent of the current, continuing need for long-stay beds. The change in size of the chronic inpatient population over time can be monitored from a given day by observing the rate at which the group in hospital on that day is reduced by death and discharge, and separately counting the number of new patients who have become long-stay since that day. Thus in Table III we start on the

TABLE II

NUMBER OF ADMISSIONS EACH YEAR WHICH LASTED ONE YEAR OR MORE

\begin{tabular}{|c|c|c|c|c|c|c|c|c|c|c|c|}
\hline \multicolumn{4}{|c|}{ Admission Year } & \multicolumn{2}{|c|}{ Schizophrenia } & \multicolumn{2}{|c|}{ Dementia } & \multicolumn{2}{|c|}{ All Other Diagnoses } & \multicolumn{2}{|c|}{ Total } \\
\hline $\begin{array}{l}1964 \\
1965 \\
1966 \\
1967 \\
1968 \\
1969 \\
1970 \\
1971\end{array}$ & $\begin{array}{l}\cdots \\
\cdots \\
\cdots \\
\cdots \\
\cdots\end{array}$ & $\begin{array}{l}\ldots \\
\ldots \\
\ldots \\
\cdots \\
\cdots \\
\ldots\end{array}$ & $\begin{array}{l}\cdots \\
\cdots \\
\cdots \\
\cdots \\
\cdots \\
\cdots\end{array}$ & $\begin{array}{r}7 \\
10 \\
9 \\
7 \\
12 \\
7 \\
6 \\
17\end{array}$ & $\begin{array}{r}(5 \cdot 7) \\
(5 \cdot 8) \\
(5 \cdot 1) \\
(7 \cdot 5) \\
(4 \cdot 5) \\
(3 \cdot 2) \\
(10 \cdot 1)\end{array}$ & $\begin{array}{r}22 \\
20 \\
15 \\
14 \\
14 \\
9 \\
10 \\
8\end{array}$ & $\begin{array}{l}(32 \cdot 8) \\
(31 \cdot 9) \\
(25 \cdot 9) \\
(32 \cdot 6) \\
(20 \cdot 5) \\
(22 \cdot 7) \\
(17 \cdot 0)\end{array}$ & $\begin{array}{r}11 \\
8 \\
10 \\
7 \\
10 \\
13 \\
14 \\
17\end{array}$ & $\begin{array}{l}(1 \cdot 6) \\
(2 \cdot 1) \\
(1 \cdot 3) \\
(1 \cdot 6) \\
(2 \cdot 0) \\
(2 \cdot 2) \\
(2 \cdot 7)\end{array}$ & $\begin{array}{l}\mathbf{4 0} \\
38 \\
34 \\
28 \\
36 \\
29 \\
30 \\
42\end{array}$ & $\begin{array}{l}(5 \cdot 2) \\
(5 \cdot 1) \\
(3 \cdot 9) \\
(4 \cdot 4) \\
(3 \cdot 4) \\
(3 \cdot 5) \\
(5 \cdot 0)\end{array}$ \\
\hline
\end{tabular}


TABLE III

PATIENTS IN HOSPITAL ONE YEAR OR MORE ON 31 DECEMBER EACH YEAR, 1964-72

\begin{tabular}{|c|c|c|c|c|c|c|c|c|c|c|c|}
\hline & & & \multicolumn{9}{|c|}{ Census Date } \\
\hline \multicolumn{3}{|c|}{ Patients } & Dec. 64 & Dec. 65 & Dec. 66 & Dec. 67 & Dec. 68 & Dec. 69 & Dec. 70 & Dec. 71 & Dec. 72 \\
\hline $\begin{array}{l}\text { Original group ... } \\
\text { ‘New' long-stay }\end{array}$ & 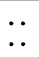 & $\because$ & 410 & $\begin{array}{r}370 \\
37\end{array}$ & $\begin{array}{r}330 \\
58\end{array}$ & $\begin{array}{r}295 \\
71\end{array}$ & $\begin{array}{r}275 \\
68\end{array}$ & $\begin{array}{r}250 \\
72\end{array}$ & $\begin{array}{r}231 \\
70\end{array}$ & $\begin{array}{r}203 \\
69\end{array}$ & $\begin{array}{r}188 \\
85\end{array}$ \\
\hline Total .. & $\ldots$ & $\ldots$ & 410 & 407 & 388 & 366 & 343 & 322 & 301 & 272 & 273 \\
\hline
\end{tabular}

census day at the end of 1964 with 410 patients (see Hailey, 1973). This group is shown in the top line of the table, decreasing year by year. The lower line shows the accumulation of a replacement group: starting at zero in 1964, there were 37 new long-stay patients at the end of 1965 . These are those of the admissions in 1964 who had become long-stay and who were still in hospital on 31 December 1965. They had all been in hospital one but less than two years. Similarly, the 58 in 1966 comprise those of the 37 still in hospital plus those from admissions in 1965 who were still in hospital at the end of 1966. At the end of 1968, 68 patients who had a stay of one but less than five years had accumulated; and so on. The figures represent an exact count of accumulation of new long-stay patients. Because these patients, after a year in hospital, had a high rate of death and discharge over the next few years, accumulation did not continue to build up but is seen to flatten off to a plateau after three to four years. The level of accumulation from 1967 to 1971 (about 70 patients) was equivalent to a rate of 41 per 100,000 total population or 53 per 100,000 aged 15 or over. However, by 31 December 1972 net accumulation was higher, the direct result of the extra long-stay admissions in 1971 discussed above.

Table IV shows the characteristics of the 85 newly accumulated long-stay patients on 31 December 1972. More than half were aged 65 or over.
The numbers in each diagnostic group for both sexes together were very similar, but whereas the number of male and of female schizophrenics were equal, in the other two groups women were predominant. The general picture is of elderly women and younger men, women outnumbering men in the whole group by about three to one.

\section{Day Patients}

The development of day care in Camberwell was described above. Table $\mathrm{V}$ shows clearly the expansion that has taken place (the data were systematically collected only from 1965; the table therefore begins with a census on 31 December 1965.) It is the local authority places that have increased, largely accounting for the fact that the number of people in day care had more than doubled, from 56 to 118 , over the seven-year period.

It is interesting to compare these figures with those published recently for Birmingham (Hassall, Gath, and Cross, 1972). A census was taken in November 1968 to examine the characteristics of patients attending the four psychiatric day hospitals which serve the city. Unlike Camberwell, Birmingham is well provided with day hospitals but has no local authority centres. The number of places (647) was equivalent to about 0.5 per 1,000 population.

TABLE IV

NEW LONG-STAY INPATIENTS ON 31 DECEMBER 1972-ACCUMULATED SINCE DECEMBER 1964

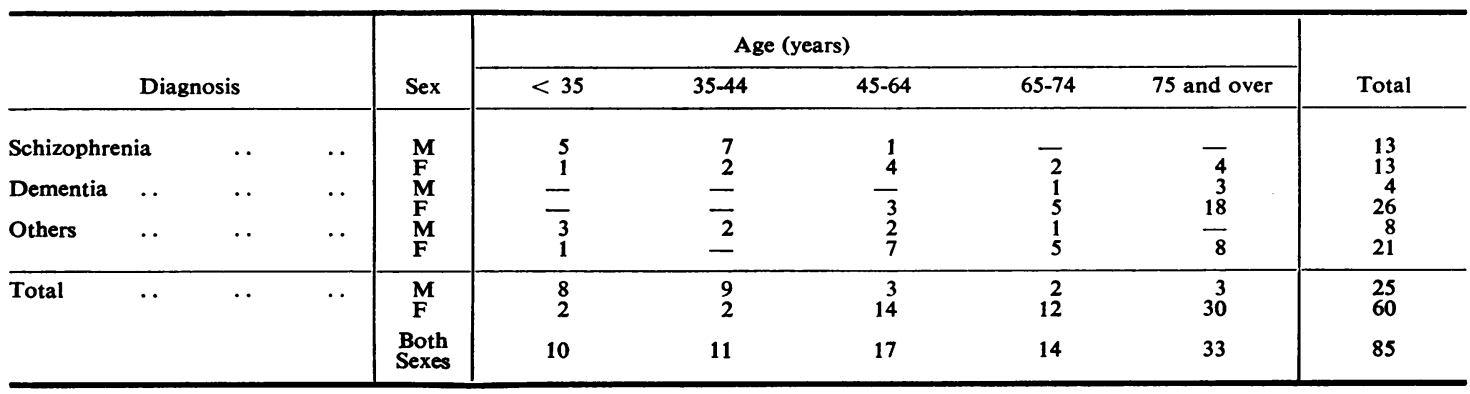


TABLE V

CAMBERWELL RESIDENTS ATTENDING DAY HOSPITALS, DAY CENTRES, AND WORKSHOPS ON 31 DECEMBER EACH YBAR, 1965-72

\begin{tabular}{|c|c|c|c|c|c|c|c|c|}
\hline \multirow[b]{2}{*}{ Type of Day Care } & \multicolumn{8}{|c|}{ Census Date } \\
\hline & Dec. 65 & Dec. 66 & Dec. 67 & Dec. 68 & Dec. 69 & Dec. 70 & Dec. 71 & Dec. 72 \\
\hline $\begin{array}{l}\text { Maudsley Day Hospital } \\
\text { Maudsley rehabilitation unit }\end{array}$ & 22 & 9 & 17 & 15 & 15 & 19 & 26 & 26 \\
\hline $\begin{array}{l}\text { (not attending Day Hospital) } \\
\text { Local Authority day centres } \\
\text { Private workshops, Remploy }\end{array}$ & $\begin{array}{l}\overline{23} \\
11\end{array}$ & $\begin{array}{l}\overline{29} \\
13\end{array}$ & $\begin{array}{r}5 \\
34 \\
15\end{array}$ & $\begin{array}{l}14 \\
49 \\
10\end{array}$ & $\begin{array}{r}9 \\
46 \\
8\end{array}$ & $\begin{array}{r}17 \\
55 \\
8\end{array}$ & $\begin{array}{r}14 \\
58 \\
9\end{array}$ & $\begin{array}{l}18 \\
63 \\
11\end{array}$ \\
\hline Total & 56 & 51 & 71 & 88 & 78 & 99 & 107 & 118 \\
\hline
\end{tabular}

The Camberwell figure in 1972, half of which is accounted for by local authority centres, was equivalent to $0 \cdot 7$ per 1,000 .

The characteristics of Camberwell day patients on 31 December 1972 are shown in Table VI. Some $44 \%$ (52 out of 118 ) had a length of stay of one year or more; $38 \%$ were schizophrenic. These figures compare with $41 \%$ long-stay in Birmingham and $36 \%$ schizophrenic. A major diagnostic difference between the two areas is the higher

\section{TABLE VI}

CAMBERWELL RESIDENTS ATTENDING DAY HOSPITALS, DAY CENTRES, AND WORKSHOPS ON 31 DECEMBER 1972

\begin{tabular}{l|cc|cc|c}
\hline \multirow{2}{*}{ Diagnosis } & \multicolumn{2}{|c|}{ Length of Stay } & \multicolumn{2}{c|}{ Sex } & \\
\cline { 2 - 5 } & $<1$ yr & 1 yr + & M & F & Total \\
\hline Schizophrenia & 24 & 21 & 34 & 11 & 45 \\
Dementia & 2 & 1 & 2 & 1 & 3 \\
Other & 40 & 30 & 27 & 43 & 70 \\
\hline All diagnoses & 66 & 52 & 63 & 55 & 118 \\
\hline
\end{tabular}

proportion of people with senile psychosis (dementia) in Birmingham-13\% compared with less than $3 \%$ in Camberwell. This reflects again the difference in the services: one of the Birmingham hospitals specialized in geriatric day patients, whereas in Camberwell there is a psychiatric day centre for old people but very few of these are suffering from dementia. An age comparison shows $31 \%$ of patients aged 65 or over in the city compared with $14 \%$ of Camberwell patients.
In the sequel to the first paper, the same authors considered the question of the new chronic population which had built up in the day hospitals (Cross, Hassall, and Gath, 1972). From the Register we can examine the changes that have been taking place in Camberwell. In Table VII the data are divided year by year into an original longstay group and newly accumulating long-stay patients in exactly the same way as was done for the inpatients in Table III. The build-up of the new chronic population has continued and does not seem to be flattening out yet. Some data were also published by Wing and Hailey (1972).

\section{Hostels}

There were only 21 patients from Camberwell in specialized hostels at the end of 1972; seven of these were in the local Housing Association accommodation. The figures are given, by length of stay to show accumulation, in Table VIII. The increase in shorter stay people in 1971 is due to the opening of the local hostel; this is reflected the following year in an increase in the new long-stay group.

Table IX gives a comparison, by age, sex, and diagnosis, between the three groups of new chronics -inpatients, day patients, and hostel residents. As the latter two are available only from 1965, the 1972 figures for inpatients have been adjusted to show seven years' accumulation on that day. (Tables III and IV showed 85 new long-stay inpatients at the end of 1972: in Table IX the figure is 82 , the accumulation since 31 December 1965

TABLE VII

CAMBERWELL RESIDENTS ATTENDING DAY HOSPITALS, DAY CENTRES OR WORKSHOPS FOR ONE YEAR OR MORE ON 31 DECEMBER EACH YEAR, 1965-72

\begin{tabular}{|c|c|c|c|c|c|c|c|c|c|c|}
\hline & & & \multicolumn{8}{|c|}{ Census Date } \\
\hline \multicolumn{3}{|c|}{ Day Patients } & Dec. 65 & Dec. 66 & Dec. 67 & Dec. 68 & Dec. 69 & Dec. 70 & Dec. 71 & Dec. 72 \\
\hline $\begin{array}{l}\text { Original group } \\
\text { 'New' long-stay }\end{array}$ & $\cdots$ & $\cdots$ & 18 & 11 & $\begin{array}{l}11 \\
21\end{array}$ & $\begin{array}{l}10 \\
15\end{array}$ & $\begin{array}{r}5 \\
33\end{array}$ & $\begin{array}{r}4 \\
39\end{array}$ & $\begin{array}{r}4 \\
46\end{array}$ & $\begin{array}{r}4 \\
48\end{array}$ \\
\hline Total & . & $\ldots$ & 18 & 16 & 32 & 25 & 38 & 43 & 50 & 52 \\
\hline
\end{tabular}


TABLE VIII

CAMBERWELL RESIDENTS AT PSYCHIATRIC HOSTELS ON 31 DECEMBER EACH YEAR, $1965-72$

\begin{tabular}{|c|c|c|c|c|c|c|c|c|c|}
\hline & & \multicolumn{8}{|c|}{ Census Date } \\
\hline \multicolumn{2}{|c|}{ Length of Stay } & Dec. 65 & Dec. 66 & Dec. 67 & Dec. 68 & Dec. 69 & Dec. 70 & Dec. 71 & Dec. 72 \\
\hline Less than 1 year .. & $\ldots$ & 2 & 4 & 3 & 6 & 5 & 2 & 14 & 7 \\
\hline 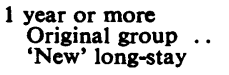 & 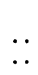 & $\underline{4}$ & $\begin{array}{l}4 \\
2\end{array}$ & $\begin{array}{l}4 \\
5\end{array}$ & $\begin{array}{l}4 \\
4\end{array}$ & $\begin{array}{l}4 \\
5\end{array}$ & $\begin{array}{l}3 \\
7\end{array}$ & $\begin{array}{l}3 \\
6\end{array}$ & 11 \\
\hline Total & $\ldots$ & 6 & 10 & 12 & 14 & 14 & 12 & 23 & 21 \\
\hline
\end{tabular}

TABLE IX

SEVEN YEARS' ACCUMULATION OF NEW LONG-STAY PATIENTS FROM CAMBERWELL ON 31 DECEMBER 1972 IN THREE TYPES OF PSYCHIATRIC CARE

\begin{tabular}{|c|c|c|c|}
\hline & Inpatients & Day Patients & $\begin{array}{c}\text { Hostel } \\
\text { Residents }\end{array}$ \\
\hline $\begin{array}{ll}\text { Age (yr) } & \ldots \\
\text { Under } 45 & \ldots \\
45-64 & \ldots \\
65 \text { and over }\end{array}$ & $\begin{array}{l}20 \\
16 \\
46\end{array}$ & $\begin{array}{l}10 \\
28 \\
10\end{array}$ & $\begin{array}{l}7 \\
3 \\
1\end{array}$ \\
\hline$\underset{\text { Female }}{\text { Male }}$ & $\begin{array}{l}24 \\
58\end{array}$ & $\begin{array}{l}28 \\
20\end{array}$ & $\begin{array}{l}4 \\
7\end{array}$ \\
\hline $\begin{array}{l}\text { Diagnosis } \\
\text { Schizophrenia } \\
\text { Dementia } \quad \ldots \\
\text { Other } \\
\end{array}$ & $\begin{array}{l}26 \\
28 \\
28\end{array}$ & $\begin{array}{r}18 \\
1 \\
29\end{array}$ & $\frac{4}{7}$ \\
\hline Total & 82 & 48 & 11 \\
\hline
\end{tabular}

rather than 31 December 1964). Over seven years 82 new long-stay inpatients, 48 long-stay day patients, and 11 long-stay hostel residents accumulated. More than half the inpatients were aged 65 or over; only one-fifth of the day patients were in the geriatric group, and one out of 11 hostel patients. There were more females than males except in the day patient group. There was a large group of chronic inpatients with dementia, one in day care, and no hostel residents with this diagnosis. Almost a third of the inpatients and over a third of the day patients were schizophrenic.

\section{CONCLUSION}

The fact that new chronic patients are arising in the psychiatric services is undeniable. Adding together the seven-year figures for Camberwell, the total was 141 , a rate of 87 per 100,000 total population (73 per 100,000 males and 101 per 100,000 females). Some of these were in the community'; 82 (51 per 100,000) were in hospitals. Projections for the future are hazardous; we have shown in this paper that a change in pattern of usage of inpatient beds in 1971-72 led to a marked increase in new long-stay inpatients at the end of 1972. A concentration of services in the local area, as opposed to the provision of beds in a distant mental hospital, has led to the multiple use of services and overlapping care: inpatient status and attendance at a day hospital are not mutually exclusive, for example, as one may lead to the other with some overlap. If we measured episodes of care we should find larger numbers of patients who could be called 'chronic' than those considered here.

The Camberwell district service, based as it is on the Maudsley teaching hospital, is still expanding. There are plans for more hostel accommodation, and a more informal type of day care has been developed at St. Francis' hospital where patients call in to the inpatient wards during the day. This study of new chronic patients serves to define the numbers and types of patients who, under the present services, make most demand on the available resources; it will be interesting in the future to see what alternatives are provided for people who need long-term care.

\section{REFERENCES}

Cross, K. W., hassall, C., and Gath, D. (1972). Psychiatric day-care-the new chronic population? Brit. J. prev. soc. Med., 26, 199.

- _ - and SPENCER, A. M. (1970). The dynamics of a long-stay mental hospital population. Brit. J. prev. soc. Med., 24, 177.

— and YATES, J. (1961). Follow-up study of admissions to mental hospitals. Some results relevant to future planning. Lancet, 1, 989.

Department of Health and Social Security (1970). Psychiatric hospitals and units in England and Wales. Inpatient statistics from the Mental Health Enquiry for the year 1968. Statistical Report Series No. 11. HMSO, London.

- (1972). Psychiatric hospitals and units in England and Wales. Inpatient statistics from the Mental Health Enquiry for the year 1970. Statistical and Research Report Series No. 4. HMSO, London. 
(1973). Psychiatric hospitals and units in England and Wales. Inpatient statistics from the Mental Health Enquiry for the year 1971. Statistical and Research Report Series No. 6. HMSO, London.

HaIley, A. M. (1973). The chronic mental hospital population: a six-year follow-up study. Brit. J. prev. soc. Med., 27, 255.

, Wing, L., and Wing, J. K. (1970). Camberwell Psychiatric Case Register. Part II: Basic data required for planning. Soc. Psychiat., 5, 195.

Hassall, C., Gath, D., and Cross, K. W. (1972). Psychiatric day-care in Birmingham. Brit. J. prev. soc. Med., 26, 112.
MAGNus, R. V. (1967). "The new chronics". Brit. J. Psychiat., 113, 555.

Mezey, A. G. and Evans, E. (1968). Towards chronic mental illness. Patients staying in hospital for more than six months. Brit. J. Psychiat., 114, 1399.

Wing, J. K. and HaIley, A. M. (eds.) (1972). Evaluating a Community Psychiatric Service, the Camberwell Register, 1964-71. Oxford University Press for Nuffield Provincial Hospitals Trust, London.

Wing, L., Bramley, C., Hailey, A. M., and Wing, J. K. (1968). Camberwell Cumulative Psychiatric Case Register. Part I: aims and methods. Soc. Psychiat., 3, 116. 